\title{
The Psychological Feelings of Newly Recruited Nurses on the Implementation of One-to-One Specialized Tutorial System Training: A Qualitative Research
}

\author{
Yanfei Li ${ }^{1}$, Jiayu Zheng ${ }^{1}$, Cuiqing Liu ${ }^{2}$, Weiju Chen ${ }^{3, *}$ \\ ${ }^{1}$ Department of Spinal and Trauma, the First Affiliated Hospital of Jinan University, Guangzhou, China \\ ${ }^{2}$ Department of Nursing, the First Affiliated Hospital of Jinan University, Guangzhou, China \\ ${ }^{3}$ School of Nursing, Jinan University, Guangzhou, China
}

Email address:

973517560@qq.com (Yanfei Li),chenweiju@126.com (Weiju Chen)

${ }^{*}$ Corresponding author

\section{To cite this article:}

Yanfei Li, Jiayu Zheng, Cuiqing Liu, Weiju Chen. The Psychological Feelings of Newly Recruited Nurses on the Implementation of One-to-One Specialized Tutorial System Training: A Qualitative Research. American Journal of Nursing Science.

Vol. 9, No. 3, 2020, pp. 102-106. doi: 10.11648/j.ajns.20200903.13

Received: March 11, 2020; Accepted: March 27, 2020; Published: April 13, 2020

\begin{abstract}
Background: Clinical tutors play an important role and responsibility in the clinical training of nurses, They are indispensable members of clinical education training and the soul of continuing education training. Clinical interns from the school into the clinical work, Clinical mentors become leaders in their careers. In the training of new nurses, the one-to-one training method of clinical tutor is also more and more popular among hospitals at home and abroad. Subject: To investigate the psychological feelings of newly recruited nurses on the implementation of one-to-one specialized tutorial system training. It is hoped to provide references for the clinical teaching and training of new nurses. Methods: Semi-structured interviews were conducted with 6 nurses whom were employed as the newly recruited nurses, and the interview data were analysed and summarized. Results: Three recurring themes emerged: (1) stress at work (2) the sense of security and belonging (3) Create a professional image and increase professional passion (4) Comprehensive ability (5) Focus on teaching methods (6) a effective method. Conclusions: The one-to-one specialized tutorial system training will bring a sense of security and belonging to the newly recruited nurses, and it could also relieve their pressure when begin their career. The tutors play a positive role in training for professional quality, shaping for professional image and the love for the career, especially at an early development stage of career growth.
\end{abstract}

Keywords: Tutorial Training, Newly Recruited nurse, Psychological Feelings, Qualitative Research

\section{Introduction}

The tutorial method of teaching originated from Oxford and Cambridge Universities since $11^{\text {th }}$ century, which was documented in the $15^{\text {th }}$ century. The tutors have responsibility for the conduct and instruction for their younger colleagues [1]. The tutorial today still remains its distinctive role in education which was described as the 'jewel in the crown' [2] Students are taught individually in small groups, which emphasize the individualized teaching methods in a harmonious and free learning atmosphere, the teaching content that pays equal role to morality and wisdom. The tutorial method of teaching has been introduced into the teaching process of higher education and gradually is becoming very popular in modern education, an increasing number of studies have showed plenty of advantages with this teaching method in nurse training $[3,4]$.

The newly recruited nurses are full of enthusiasm for work, but there are some challenges to be overcome for them, they always produce a feeling of insecurity, instability and anxiety [5]. Their also have poor psychological endurance and social adaptability, no confidence in skills. They should take some time to get used to the new environment, the new interpersonal relationships and hospital communication [6]. All of these conditions could easily cause them have an unstable emotion, which may lead them have a negative emotions on clinical work, thus affecting the quality of nursing or causing turnover their jobs. This is a serious problem that facing all countries in 
the world. According to the Kovner's study [7], 13\% of new registered nurses leave their jobs in their first year of professional practice, and additional $37 \%$ were thinking about leaving. Unruh found that $18 \%$ of new nurses had left their first job, and $23 \%$ had a desire to change jobs [8]. As a result, the nursing human resources were in shortage since the high rate of nurse job turnover, It is relatively common in China, accounting for $13.24 \%$ in the nursing human resources, among which the eastern region is the most obvious, with a rate of $18.69 \%$, while the central of $14.21 \%$ and the western region of $10.43 \%$ [9].

However, the mentorship system can play an active role in nurse professional self-identity which could be benefit for occupation plan. Our department has adopted the tutorial system for the newly recruited nurses since 2018. In this study, we will investigate the psychological feelings of newly recruited nurses in their first year's employment on the implementation of one-to-one specialized tutorial system training, and try to understand what we can do for the newly recruited nurses when they transfer their status into clinical practice.

\section{Methods}

\subsection{Participants}

Using the method of target sampling, we did an interview with nurses who work from May 2018 to August 2019 in the department of orthopedics, the first affiliated Hospital of Jinan University. The inclusion criteria were nurses who have been worked within 2 years, have received clinical tutorial system training and have willing to participate in this research.

\subsection{Procedures}

All participants completed a face-to-face, semi-structured, interview. The interview was conducted after the daily work. All interviews were performed face-to-face by the first author in a quiet location. All interviews were audio-recorded with consent. The interview lasted an average of $45 \mathrm{~min}$, ranging from 25 to $58 \mathrm{~min}$. The information saturated sample size is appropriate. Before the interview, the researcher introduces the purpose and significance of the study to the research object, and obtains the consent of the interviewee for the recording question. In order to protect the privacy of patients, all the research content is anonymous and the name is numbered instead.

\subsection{Data Collection}

A semi-structured, interview was developed for this study that included open-ended questions such as: 1) What's your opinion on the implementation of one-to-one specialized tutorial system training? 2) What's the effect of tutorial system training on your passion for your career? 3) What is your ideal type of clinical tutor? 4) What is your ideal clinical teaching method? Each question is followed by probing question such as "Please explain more", and/or "Can you give an example?" Interviewing skills were required, such as active listening and asking open-ended questions without hidden presumption, building rapport and trust. During the interview, nonverbal information was also noted and integrated into the transcript.

\subsection{Data Analysis}

Colaizzi's 7-step method [10] was used to analyze the data. 1) To interpret the record materials and read it carefully. 2) To extract the meaningful statements. 3) Coding the recurring and meaningful ideas. 4) To summarize the ideas. 5) Writing a detailed and seamless description. 6) To identify similar points of view, sublimate the theme concept. 7) Return to verification. memos were used to record the reflections during data analysis and integration. The meaningful statements were extracted based on the objects expression, tone, eyes, silence time and body movements. The two researchers coded and classified independently, they extracted themes, valued and compared the data, both sides reached an agreement in the end.

\subsection{Ethical Issues}

Personal privacy may be involved in the study, the researchers followed the rules when they dealed with ethical issues: Researchers introduced the aim of this program. Recording could not be conducted before obtaining the agreements form interviewee. Subjects have the right to withdraw. Researches to express thanks to the subjects attendance and could be inspired and benefited during the interview.

\section{Results}

\subsection{Participants}

A total of 6 interviewees were included in this study. Interviewees were between 23 and 29 years of age, with an average of $25.3 \pm 2.3$ years. who have worked for 7 to 12 months. Academic qualifications include Technical secondary school (16.7\%), Junior College (33.3\%), Undergraduate (50\%). Participants' characteristics are presented in Table 1.

Table 1. General information of the participants $(n=6)$.

\begin{tabular}{llllll}
\hline number & gender & Age (years) & Degree level & Working years (months) & Years of experience of tutor (years) \\
\hline P1 & female & 25 & Undergraduate & 8 & 10 \\
P2 & female & 29 & Junior college & 11 & 7 \\
P3 & female & 26 & Junior college & 10 & 9 \\
P4 & female & 26 & Technical secondary school & 12 & 7 \\
P5 & female & 23 & Undergraduate & 8 & 7 \\
P6 & female & 23 & Undergraduate & 7 & 10 \\
\hline
\end{tabular}




\subsection{Themes}

\subsubsection{Stress at Work}

We found the majority of nurses faced with stress at work with unfamiliar environment in their first year of work, which could be caused by immature technology, workflow and unharmonious human relations, the psychological feelings still occur when they try to get used to the clinical fast-paced. In addition, exam-oriented in nursing education has a disadvantage that the disconnection between practice and theory render the nurse students with low abilities in China, which also leads to the difficulty for nurses to adapt to the new environment when they enter clinical work. The one-to-one specialized tutorial system training could reduce the stress at work environment. P3 "It was stressful at the beginning since I felt like I didn't know anything and had to learn everything". P2 "It is still very stressful owing to I have to relearn the new working system and readapt interpersonal relationship in the hospital even if I have worked in the other hospital". P5 "I feel that the knowledge in school is beyond the clinical practice, especially in the communication, we have been taught by plenty of knowledge on the theoretical examination, but less for the clinical practice". P1 "I have worked as an internship in this hospital and am familiar with the environment, but I don't know much about the other aspects". P6 "It is very difficult to communicate with the patient since humanistic relations are less learned in school and only stay in the paper version of the exam".

\subsubsection{The Sense of Security and Belonging}

The tutorial training could enhance the sense of security and belonging. The newly recruited nurses could always have opportunity to ask questions from their tutors in any conditions, tutors could bring a sense of security and belonging to their nurses, and they can know who to ask for help when they encounter problems in work and study. Even when they encounter problems during the rest time, they can also ask for help from their own mentors. All of the 6 subjects are content with this. P4 "I will think of my tutor at the first time when I meet the difficulties rather than others". P3 "She can give me a sense of security and belonging". P2 "I will have a sort of depended mind when I work with my mentor". P4 "I feel she is my family member since she take care of my life and ease my anxiety produced when I move to this new environment".

\subsubsection{Create a Professional Image and Increase Professional Passion}

The tutorial training could increase the love for their chosen career by the professional image which shaped by their tutors. Four subjects in our study did not chose nursing as a first choice for their career, they were forced to choose it because of the various other reasons, so the love for nursing career was probably about $50 \%$ when they were employed. However, this love will gradually increase when their patients get better with their professional care, and the professional which shaped by their tutors will increase their love for this profession as well.
P5 "My tutor said that our community will get much more respects when we are becoming stronger enough and it doesn't relevant to the career eventhough these are some prejudice against the nurses, My tutor's personality and professional image influenced me a lot". P2 "I choose the nursing major because of my parents as it is easier to find a job, I enjoy it when my patients are getting better, I felt a sense of accomplishment and gradually fell in love with this profession". P1 "My tutor told me that I could do much more for the patient if I continue to study".

\subsubsection{Comprehensive Ability}

Our 6 subjects hoped that their tutors would be a high-qualified nurse with noble morality and first-class technology. Their communication skills were contented by 5 subjects, but no one mentioned about their computer skills or writing ability. P6 "I hope she is a person with theoretical knowledge, specialized skills and strong communication skills". P4 "I hope she has professional theoretical foundation and skillful practice". P3 "I hope she has rich experience and the ability to deal with emergencies".

\subsubsection{Focus on Teaching Methods}

All of our subjects prefer to methods instead of results in terms of teaching, and their would like to keep up with their tutor's pace. P1 "I hope my teacher would be there to guide me and supervise me instead of doing for me". P3 "I hope my tutor can point out my problems in time". P6 "I like the model that allows me to make my own judgments but doesn't let me off the hook".

\subsubsection{A Effective Method}

All of our subjects agree with that it is the most opimal method for the one-to-one specialized tutorial system training. The duration of the training with the tutor varied according to the growth rate of different people. P2 "One-to-one tutorial training is very good. teachers and students are familiar with each other when there is a certain teacher, she knows about my shortcomings." P4 "My tutor knows my shortcomings, so my tutor will pay more attention to my work when I encounter with the same problem". P6 "Work with a mentor first, and then with other teachers if you are familiar with all the processes. I can learn more about the strengths of others when collaborate with the other tutors". P5 "This is a good method. I hope I could follow my tutor for 3 months at less, I can study the majority of our practice, so that I can work with more confidence in the future".

\section{Discussion}

The nurse-to-bed ratio is far lower in the majority hospital in China than the international level, and the nursing human resources can not meet the practical needs of clinical. As a result, the workload for nurses per patient is increasing. Together with the current tense physician-patient relationship, more and more young people are reluctant to engage in the medical area. The stress at 
work is also an important factor for the nurses leaving, especially for the nurses with junior training and less education [11]. In China, It represents the generations are born in the 1980s and 1990s, they are the single children in family since of one-child policy. Their resilience of pression is fragile, they are easily to give up their job and return to family. In this situation, Their tutors can propose specific learning objectives and make relevant plans according to the individual abilities of nurses, so as to help them grow up gradually. Their tutors are more conducive to improve the post competence of nurses and the intention of selecting departments [12]. In particular, one-to-one specialized tutorial system training can enable the tutor to know more about their students' clinical learning and psychological feelings, and the tutor can follow up and solve problems in time. According to our system training, the newly recruited nurses have a good relationship with their mentors, they will have a sense of security and belonging to their department, thus promoting them to love their career.

Mentors should enhance the professional image of new nurses so as to enhance their love for their profession. As an important source of knowledge and experience, the tutors set a good model for their nurses students, the new nurses will have a higher requirements for themselves with the influence of their tutor's personality. The nurses will have a correct outlook on life and values by the tutors' words and deeds, all of this will stimulate their enthusiasms and have a clearer understanding of the nursing career, and virtually improves their understanding of the professional connotation and professional identification $[13,14]$.

The ideally tutor should be both ability and political integrity, good knowledge and noble virtues. The tutors would be a high-qualified nurse with noble morality and first-class technology, the students hope to have the same personality and facilitate communication with their tutors. Effective mentoring education can benefit future nursing professionals, students' satisfaction and learning, as well as the general perception of the nursing profession [15]. Clinical mentors have significant roles and responsibility for nursing students' clinical learning [16]. Tutors should have diverse capabilities to meet the needs of clinical students. The international nursing standard defines 8 competences distinguishing the responsibilities of mentors: 1) Mentors are expected to facilitate the progress of the students towards achieving results. 2) To establish an efficient working relationships. 3) To facilitate learning. 4) To assess and evaluate the student learning experience. 5) To create a suitable environment for learning. 6) To apply theory into practice, implement scientifically proven practices. 7) To assist in the identification and achievement of the learning objectives of the students. 8) Participation in the formation of an overall evaluation of the students trained in the conditions of clinical practices, and guarantees the mastering of clinical competences [17]. The training tutors should meet the expectations of students, and this could be a positive pattern for teaching is learning. These documents show that in developing criteria for selecting mentors, work experience and level of education should be taken into account. in addition to the required educational qualifications and work experience of the mentor, her personal qualities and teaching skills also play avery important role [18].

\section{Conclusions}

The one-to-one specialized tutorial system training can bring a sense of security and belonging to the newly recruited nurses, and it could also relieve their pressure when begin their career. At the same time, it is also helpful to establish a good teacher-student relationship and promote communication between teachers and students, the tutors play a positive role in training for professional quality, shaping for professional image and the love for the career, especially at an early development stage of career growth. The method has been established in the clinical, it is easier to improve clinical skills and working methods, and increase the nurses' professional self-identification, which is worthy to promote and apply in China.

\section{Conflict of Interest}

The authors declare that they have no conflict of interest.

\section{References}

[1] Moore, W. G. (1968). The Tutorial System and its Future. (Oxford: Pergamon Press).

[2] Palfreyman, David ed. (2008). The Oxford Tutorial. (Oxford: OxCHEPS).

[3] C Y Akinsanya. Tutorials in Nurse Education: A Survey of Its Use in District Nursing Training [J]. Nurse Educ Today. 1992, 12 (4): 303-9.

[4] McDonough K, Crimlisk J, Nicholas P, etal. Standardizing nurse training strategies to improve knowledge and self-efficacy with tracheostomy and laryngectomy care [J]. Appl Nurs Res. 2016, 32: $212-216$.

[5] Duchscher JE. Transition shock: the initial stage of role adaptation for newly graduated registered nurses [J]. J Adv Nurs. 2009, 65 (5): 1103-1113.

[6] Casey K, Fink R, Krugman M, etal. The graduate nurse experience [J]. J Nurs Adm. 2004, 34 (6): 303-311.

[7] Kovner CT, Brewer CS, Fairchild S, etal. Newly licensed RNs' characteristics, work attitudes, and intentions to work [J]. Am J Nurs. 2007, 107 (9): 58-71.

[8] Unruh LY, Zhang NJ. Newly licensed registered nurse job turnover and turnover intent [J]. J Nurses Prof Dev. 2014, 30 (5): 220-E9.

[9] Hongmei Tang. Strategy research on nursing education [D]. Zhejiang University. 2012.

[10]Liu M. Using an example to illustate Colaizzi's phenomenological data analysis method [J]. Journal of Nursing Science. 2019, 6 (34): 11-12. 
[11] Gao ZY, Li GH. The reason analysis and countermeasure of the loss of nurses in a grade a hospital [J]. Jiangsu health administration. 2013, 24 (6): 36-37.

[12]Zheng QL, Zhang CL, Li X, et al. A study on the influence of the tutorial system on the competence and intention of ICU nurses $[\mathrm{J}]$. Continuing medical education in China, 2019, 11 (10): 26-29.

[13]Li JQ, Wen XL, Zhang YP. To explore the application of the "growth mentor companion system" in the standardized training of new nurses [J]. Chinese medical ethics, 2018, 31 (11): $1422-1426$.

[14]Jones SJ. Establishing a Nurse Mentor Program to Improve Nurse Satisfaction and Intentto Stay [J]. J Nurses Prof Dev. 2017, 33 (2): 76-78.14

[15]Tuomikoski AM, Ruotsalainen H, Mikkonen K, et al. How mentoring education affects nurse mentors' competence in mentoring students during clinical practice - A quasi-experimental study [J]. Scand J Caring Sci. 2020, 34 (1): 230-238.

[16]Pramila-Savukoski S, Juntunen J, Tuomikoski AM, et al. Mentors' self-assessed competence in mentoring nursing students in clinical practice: A systematic review of quantitative studies [J]. J Clin Nurs. 2020, 29 (5-6): 684-705.

[17]Doynovska R, Krasteva S, Antova D. Importance of nursing documentation in the training of patients with chronic pulmonary diseases [J]. Preventive Medicine magazine. 2012, (2): 27-29.

[18]Dragusheva S, Petleshkova P, Panova G. Incentives. Motivating Mentors and Criteria for Selecting Mentors in the Pre-Graduation Traineeship of Future Registered Nurses [J]. Open Access Maced J Med Sci. 2019, 7 (19): 3294-3297. 